\title{
Melodrama, peça bem feita e a questão da homoafetividade em The children's hour, de Lillian Hellman ${ }^{1}$
}

Fulvio Torres FLORES ${ }^{2}$

(Universidade Federal do Vale do São Francisco)

\begin{abstract}
RESUMO: A proposta deste artigo é analisar a recepção da crítica em língua inglesa em relação à peça The Children's Hour, de Lillian Hellman, focando no entrelaçamento dos elementos da peça bem feita e do melodrama com a temática da homoafetividade abordada no texto dramatúrgico. Para isso, foram reunidos os artigos e ensaios mais relevantes da estreia da peça em 1934 à encenação mais recente em 2011, a fim de mostrar que a crítica encontrou mudanças substanciais no que concerne à abordagem da homoafetividade, mas ainda se perpetua uma avaliação desfavorável sobre as escolhas formais de Hellman, prejudicando o entendimento da vitalidade do texto.
\end{abstract}

PALAVRAS-CHAVE: The Children's Hour, Peça bem feita; Melodrama; Homoafetividade; Teatro NorteAmericano.

ABSTRACT: This article aims to analyze the critical reception in English related to Lillian Hellman's play The Children's Hour, focusing on the intertwinement of the well-made play and melodrama elements with the homoaffectivity broached in the dramaturgical text. To achieve this purpose, the most relevant articles and essays from the first performance in 1934 to the most recent one in 2011 have been collected in order to show that critics have found substantial changes concerning the homoaffectivity theme in the play, however, it is still perpetuated an unfavorable evaluation of Hellman's formal choices, harming the understanding of the play's vitality.

KEYWORDS: The Children's Hour; Well-made play; Melodrama; Homoaffectivity; North-American Theater.

\section{INTRODUÇÃO}

The Children's Hour (Calunia) ${ }^{3}$, primeira peça escrita por Lillian Hellman, estreou em 20 de novembro de 1934 no Maxine Elliott Theatre, em Nova York. Ficou em cartaz por dois anos, com um total de 691 apresentações. Na Broadway, a peça nunca foi censurada por ter entre seus temas principais a homoafetividade, porém, Hellman e o diretor Herman Shumlin não teriam a mesma sorte em outras cidades, como Boston, Chicago e Londres, que a proibiram.

Neste artigo será usado o termo homoafetividade porque esse expressa o aspecto sentimental (amor, afeto, carinho etc.) entre pessoas do mesmo gênero, o que tem relação direta com a narrativa da peça. Dispensa-se, portanto, o uso do termo homossexualidade pois esse é, em geral, usado de forma restrita, focando pejorativamente no aspecto sexual.

A peça voltou a ser encenada na Broadway em 1952, dirigida pela própria autora. É uma das peças mais encenadas de Hellman, principalmente no circuito universitário norte-americano. Em 2011, Londres recebeu uma montagem profissional da peça com direção de Ian Rickson, tendo no elenco Keira Knightley (Karen Wright), Elizabeth Moss (Martha Dobie), Ellen Burstyn (Sra. Amelia Tilford), Bryony Hannah (Mary Tilford) e Carol Kane (Sra. Lily Mortar).

\footnotetext{
1 Este artigo apresenta uma versão revista, ampliada e atualizada de parte do estudo realizado em minha dissertação de mestrado "Nem só bem feitas, nem tão melodramáticas: The Children's Hour e The Little Foxes, de Lillian Hellman", defendida em 2008.

2 Professor Adjunto no Curso de Artes Visuais da Fundação Universidade Federal do Vale do São Francisco (UNIVASF) Doutor em Estudos Linguísticos e Literários em Inglês, USP. E-mail: fulvio.flores@univasf.edu.br

3 Os nomes de peças e livros serão usados no original em inglês, e somente na primeira aparição dos mesmos será apresentada sua tradução. Calúnia foi o título atribuído pelo tradutor Gustavo Dória.
}

(C) Revista Moara, n.41, jan.- jun. 2014, Estudos Literários. ISSN 2358-0658 (Impresso).

Programa de Pós-Graduação em Letras / Universidade Federal do Pará. Todos os direitos reservados. 


\section{MELODRAMA, PEÇA BEM FEITA E A ESTRUTURA DRAMATÚRGICA EM DEBATE}

Iniciando a discussão proposta, Brooks Atkinson, um dos grandes críticos teatrais do século XX nos E.U.A., afirma sobre a estreia da peça:

Lillian Hellman escreveu uma peça maliciosamente trágica da vida em um internato
para moças - afiando na agudeza de seu estilo dramático e na precisão mortal da
interpretação. Nos últimos dez ou quinze minutos do último ato, ela tenta
desesperadamente descobrir uma conclusão dramática vigorosa. Tendo afastado The
Children's Hour do teatro para a esfera do humano, ela a empurra de volta entre as
bonecas ibsenianas e enfeita, recusando-se a parar de falar. Por favor, Miss Hellman,
conclua a peça antes do tiro de pistola e da longa série de coincidências que começa a
chacoalhar no seu cartucho. Quando duas pessoas são derrotadas pela maldade da
opinião pública, deixe-as com a dignidade de seu ódio e desespero. ${ }^{4}$ (ATKINSON,
1934a, p. 23)

Quando diz que há uma longa série de coincidências, Atkinson se refere a um aspecto melodramático que identifica na peça. Para ele, há uma sucessão de acontecimentos forçados não naturais na ordem do que os críticos chamam de vida cotidiana - no terceiro ato, após as professoras Karen e Martha terem perdido o processo contra a Sra. Tilford. Sabemos da derrota delas pelos diálogos no início do terceiro ato (na versão fílmica de 1961, homônima à peça e dirigida por William Wyler, foi criada uma cena do processo).

O terceiro ato tem início com ambas as professoras sozinhas na casa. Não há qualquer perspectiva de que consigam emprego na própria cidade ou fora dela. Os moradores de Lancet as rejeitam completamente e o único contato que elas têm tido é com um entregador de compras. Não há, portanto, projeção de um futuro tranquilo. Pode-se resumir a sucessão de acontecimentos criticada por Atkinson da seguinte forma:

- a Sra. Mortar (tia de Martha) chega de sua turnê teatral e dá uma desculpa esfarrapada sobre não ter podido testemunhar a favor da sobrinha e de Karen;

- Joe (noivo de Karen) chega à casa e, em uma discussão com a noiva, ela pede que ele vá embora;

- Martha revela que realmente nutria amor por Karen;

- Martha se suicida;

- a Sra. Tilford visita Karen para dizer que descobriu toda a verdade sobre as armações de sua neta, Mary Tilford.

Se a forma da peça for analisada seguindo apenas preceitos de construção dramática e melodrama, é possível concordar com o crítico Brooks Atkinson. A sucessão de acontecimentos do terceiro ato aponta para uma construção melodramática baseada em um mecanismo artificial. Há, porém, de se levar em conta que o conteúdo trabalhado nos dois atos precedentes pede respostas. Poderia até se alegar se não seria o caso de distribuir os acontecimentos do último ato em outros dois, com uma possível distribuição sendo: no terceiro ato, chega a Sra. Mortar, Karen rompe com Joe e ele vai embora; no quarto ato, Martha revela seus sentimentos, suicida-se e em seguida chega a Sra. Tilford. Tal divisão não alteraria o conteúdo, dando conta apenas de distribuir mais parcimoniosamente a ação e causando mudança no arcabouço formal.

Atkinson (1934a) concentra sua crítica sobre a vilania de Mary Tilford e as consequências nefastas que seus atos geram, e não sobre as condições que permitem que Mary destrua a vida das professoras Karen e Martha. Para Atkinson, deixar as personagens com a dignidade de seu ódio e desespero seria um final plausível para a peça. A implicação disso, porém, seria não

\footnotetext{
4 Todos os textos citados foram originalmente escritos em língua inglesa e traduzidos pelo autor do artigo.
} 
resolver dramaticamente (no sentido de carpintaria dramatúrgica) as outras questões levantadas.

Quando Atkinson (1934a) sugere que as personagens sejam deixadas "à dignidade de seu ódio e desespero", ele está atingindo o ponto crucial e mais polêmico da peça ao longo de décadas: a confissão de amor de Martha a Karen. Sem a confissão de amor de Martha a peça continuaria fazendo sentido, pois a força motriz do enredo é a mentira levantada por Mary, espalhada pela avó e aceita pela sociedade. Hellman, ao contrário, não se esquiva de explorar uma temática que ela mesma levantou, isto é, ela não assume a posição conservadora de concluir a peça sem explicar ao espectador se havia ou não fundamento nas acusações da Sra. Mortar e de Mary. Isto porque a autora tem domínio completo sobre seu trabalho e sabe que a questão da homoafetividade não é a questão principal da peça. Como será visto mais adiante, a decisão da autora em fazer com que Martha confesse também abala o conceito de peça bem feita.

O crítico da revista New Yorker Robert Benchley (1934, p. 34) afirma que a peça tem "[...] muitos finais, qualquer um deles teria sido suficiente". Por finais, entendam-se a partida de Joe (que ele considera desnecessária), a confissão e o suicídio. É curioso Benchley afirmar que qualquer um dos finais seria suficiente, pois cada um deles resolve um aspecto específico da peça, especialmente porque a confissão e o suicídio de Martha estão intimamente ligados à partida de Joe. Quando Karen conta que Joe foi embora definitivamente, Martha tenta pela derradeira vez se convencer de que seus sentimentos pela amiga de longa data são apenas fraternais. Karen então pergunta a ela o porquê de dar tantas explicações, e Martha decide que não há mais motivos para esconder seu sentimento, confessando que ama Karen "[...] do jeito que eles disseram" (HELLMAN, 1971, p. 65).

O suicídio de Martha é intrinsecamente ligado à sua confissão. Se o final escolhido por Hellman fosse de que Martha apenas confessaria e não se suicidaria, as personagens seriam deixadas à dignidade de seu desespero, como Atkinson sugerira, mas um elemento geraria uma incongruência grave: ao deixar Martha viva e abandonada na casa com Karen, o entendimento do final da peça seria diferente. Haveria a possibilidade de interpretar que Karen dispensou Joe pensando em Martha; que Karen, apesar de todos os problemas, vê no relacionamento com outra mulher uma possibilidade ${ }^{5}$ que Mary não estava mentindo completamente. Como esses acontecimentos pertencem todos ao último ato, a crítica à forma é inevitável. Ainda em 1934 Brooks Atkinson (1934b, p.11) tece algumas considerações sobre a peça bem feita para realçar o que não o agrada:

\begin{abstract}
Embora seja impossível dizer o que pessoas farão em certas circunstâncias, é possível sentir-se bastante aflito quando um dramaturgo está deixando a técnica postergar seu tema. Miss Hellman está determinada a fazer de The Children's Hour uma peça simétrica. Sua ingenuidade técnica castra sua importância nos últimos minutos do ato final. Pela intensidade de sua convicção em todo o resto da peça ela mostrou como as circunstâncias ergueram a opinião pública contra Karen e Martha e estigmatizam-nas como exiladas sociais. A vida pode fazer isso e indiscriminadamente o faz todos os dias. Tendo marcado sua opinião com uma impiedade que deixa todos nós perplexos pela fúria daquilo que testemunhamos, a técnica de Miss Hellman então começa a amarrar os fios soltos na história.
\end{abstract}

Atkinson responde a observações do público sobre os problemas de plausibilidade que a peça teria. Entre esses problemas, ele indica ser duvidoso que: os adultos acreditassem em Mary; Mary e Rosalie fossem interrogadas juntas; a Sra. Tilford espalhasse o escândalo sem investigação. É por essa razão que Atkinson começa a frase com "Embora seja impossível dizer o que as pessoas farão [...]". Ele marca a posição de quem, ao contrário de muitos outros críticos, não quer acreditar naquela plausibilidade cotidiana.

Qualquer autor que faça uso da peça bem feita deixa seu arcabouço à vista. Quando não é possível identificar o arcabouço (ou estrutura) em uma peça bem feita, então não se está diante de

\footnotetext{
5 Como veremos mais à frente (seção 3), essa hipótese é inverossímil na narrativa da peça.
} 
uma. O fato de que Hellman deixou o arcabouço de The Children's Hour à mostra parece ter sido o que realmente incomodou Brooks Atkinson.

Atkinson se limita a criticar os últimos minutos, porém a peça faz uso de recursos da forma bem feita de maneira um pouco diversa. Apesar de não usar a palavra, é possível arriscar que o crítico está propositadamente confundindo dois conceitos que têm pontos de contato: o de peça bem feita e de melodrama. No dizer do autor, os fios soltos que ela tenta amarrar têm forte apelo emocional diretamente ligado ao conteúdo da peça. Atkinson (1934b, p. 11) continua:

\footnotetext{
Há uma confissão e um suicídio. Finalmente Miss Hellman transforma toda a peça em um episódio teatral de esperteza ao trazer a Sra. Tilford na última cena para confessar que ela cometeu um erro e para oferecer retribuição em forma de dinheiro. Após ter sido varrido do teatro pela universalidade do tema, é humilhante ter que voltar ao teatro enquanto a miscelânea da carpintaria está sendo amarrada. É como se Miss Hellman não percebesse que admirável e sensível tragédia ela escreveu.
}

É inegável que a carpintaria dramatúrgica está exposta. Vale, porém, argumentar a favor de Hellman, como já afirmado previamente em relação a Robert Benchley, que para a autora não era possível simplesmente abandonar questões que ela mesma havia levantado de forma tão contundente. Atkinson considera os momentos finais da peça uma miscelânea de amarrações, e isso está intrinsecamente ligado ao aspecto mais melodramático da peça, quando há um forte apelo para a emoção. Em 1952, ano da segunda encenação na Broadway de The Children's Hour, Atkinson (1952, p. 11) escreveu novamente para o The New York Times, desta vez criticando mais suavemente:

\footnotetext{
Aqueles dez minutos de desforra ainda estão um pouco exagerados. Miss Hellman insiste em dizer algumas coisas que são supérfluas na atordoante atmosfera da conclusão. Mas não muitas coisas. Ela precisa daquela guinada final da lésbica. Ela está encarregada de mostrar que a caluniadora está tão inteiramente condenada quanto aquelas que foram caluniadas, e que honradez é uma forma implacável de vaidade e que não há meios de se desfazer um erro cometido por meio de uma atitude hipócrita.
}

Atkinson insiste que a guinada final da lésbica não passa de um artifício teatral. Quase duas décadas depois da estreia da peça, o crítico ainda quer que as personagens sejam deixadas em seu desespero. E Hellman realmente as deixa, mas não da maneira esperada pelo crítico: Martha não suporta o desespero de ter perdido a escola e, mais importante, de ter destruído a vida de sua única amiga e seu único amor, pois foi induzida a acreditar que a origem do problema estava em seus sentimentos considerados anormais.

\section{A HOMOAFETIVIDADE DECLARADA E SEU ENTENDIMENTO PELA CRÍTICA}

A confissão do amor de Martha por Karen incomodou muito os críticos. A homoafetividade ainda era um tema tabu na década de 1950 e muitos autores lidaram com ele tangencialmente. Um exemplo é Tennessee Williams, que inseriu essa temática em algumas de suas peças que estrearam no circuito comercial da Broadway, mas em nenhuma delas há uma confissão tão clara quanto na peça The Children's Hour. Em A Streetcar Named Desire (Um Bonde Chamado Desejo - 1948), Blanche fala sobre seu marido homossexual, que se matou após ser descoberto pela esposa tendo relações sexuais com outro homem. Em Cat on a Hot Tin Roof (Gata em Teta de Zinco Quente - 1955), não há nenhuma confissão por parte de Brick Pollit, personagem principal da peça, apenas alusões ao seu relacionamento afetivo com Skipper, personagem que só é citado, pois no início da peça já se suicidara. Em Suddenly Last Summer (De Repente, no Último Verão - 1958), Sebastian Venable usa a prima como isca para atrair homens com 
os quais possa em seguida arriscar um relacionamento efêmero. Fica clara, portanto, a ousadia de Hellman em colocar nos palcos americanos em pleno ano de 1934 uma declaração de amor homoafetiva.

Em seu livro Plays of the Year: 1950-1951 (Peças do Ano: 1950-1951), o crítico J. C. Trewin (1952, p. 12) conta como a temática da homoafetividade continuava a ser um tabu na Inglaterra:

Ficamos felizes em encontrar esse teatro na ativa novamente [New Boltons, um teatro privado], e com a peça de Lillian Hellman - banida de apresentações públicas nesse país porque o crime do qual Mary falsamente as acusa é o de lesbianismo. Não há nada caçaníquel nessa peça, nada desprezivelmente repugnante; é um drama corajoso e violento $[\ldots]$

A confissão de amor de Martha incomodou muito porque ela tira da peça a força da vilania intrínseca de Mary e do poder da Sra. Tilford. Quando Martha confessa que ama Karen "do jeito que eles disseram", ela subverte uma moral melodramática fácil de ser localizada: avó e neta vilãs, professoras vítimas. Ao confessar a verdadeira natureza de seu sentimento, Martha extrapola os limites do palco e passa a ser objeto de julgamento do público. Por maior que tenha sido o sucesso em Nova York, é nítido por que os censores a barraram em várias cidades. Afinal, a autora conseguiu pôr em evidência uma questão completamente tabu. Ao mesmo tempo, denunciou o papel da sociedade naquele processo de destruição, mostrando a humanidade da personagem, que escolhe a morte como única saída por não suportar o enorme conflito inferior e as negações que já estava sofrendo ao ser destruída profissional e socialmente.

Vale retomar brevemente o que Atkinson (1934a) chamou anteriormente de esfera do humano. The Children's Hour tem parte considerável de suas ideias calcada no plano da coletividade e da crítica à sociedade conservadora. Em um melodrama comum, bastaria condenar as identidades malévolas da avó e neta. Nessa peça, o exame que se exige é mais complexo, pois requer o entendimento de todo o mecanismo engendrado na narrativa no que se refere:

- à forma perversa como a mentira é construída;

- à aceitação dessa mentira pela avó;

- à ação coletiva de retirada das meninas da escola, ação impulsionada pela força moral da Sra. Tilford naquela comunidade;

- ao embate entre as professoras e a Sra. Tilford, no qual a velha senhora afirma que elas jamais deveriam ter cuidado de crianças;

- à derrota das professoras em um processo judicial certamente marcado pela relação de compadrio do juiz com a Sra. Tilford;

- à moral social que desestabiliza até mesmo o quase inabalável Joe;

- a uma descoberta provocada por uma mentira e que leva a um suicídio;

- a uma tentativa inócua de reparos.

Uma importante contribuição para a discussão acerca da peça veio por meio de um artigo de R. C. Reynolds publicado no livro Stage Left. the development of the American social drama in the thirties (Esquerda no palco: o desenvolvimento do drama social norte-americano nos anos 1930), pois nele o autor aborda uma questão que será exposta em relação à temática da homoafetividade em The Children's Hour, mais à frente discutida também pela crítica Lynda Hart. De acordo com R. C. Reynolds (1986, p. 133), “[...] a pergunta importante levantada pela peça não é se as duas mulheres são amantes, mas se isso faz alguma diferença".

Assim, Reynolds relativiza fortemente a opinião de Richard Moody, crítico e biógrafo de Hellman, pois esse último, autor da biografia Lillian Hellman: playwright (Lillian Hellman: dramaturga), identifica elementos perturbadores para a plateia no terceiro ato: a confissão de Martha, a descoberta de que Joe não obteve sucesso ao tentar descobrir a verdade interrogando as duas meninas (Mary e Rosalie), e também não testemunhou a favor das professoras. Moody 
afirma que a confissão de Martha perturba o terceiro ato porque a confissão dá início a outra peça, "[...] sobre lésbicas que vivem em uma sociedade que pune lésbicas" (MOODY, 1972, p. 55). Ele prossegue afirmando que "[...] nossa compaixão está direcionada para duas professoras heterossexuais acusadas falsamente de lesbianismo, que estão sendo punidas por uma sociedade que pode ser pervertida por mentiras e pode tolerar a punição a inocentes" (MOODY, 1972, p. 55). Para Reynolds, Doris Falk se opõe à crítica de Moody. No entendimento dessa autora, a acusação de lesbianismo é uma metáfora, como ela explicita na biografia Lillian Hellman: "E se, afinal, uma - ou até ambas - as mulheres tivessem tais sentimentos, consciente ou inconscientemente? A 'culpa' mereceria destruição pelas mãos da sociedade?” (FALK, 1978, p. 41).

Para R. C. Reynolds, Moody e Falk se esqueceram de que a questão principal da peça é a mentira. Reynolds (1986, p. 134) lembra um importante fato histórico que ajuda a lançar luz sobre a peça:

Em 1934, a questão mais claramente à vista era o antissemitismo, evidente não apenas na Alemanha nazista, mas até mesmo na pátria norte-americana. No Reich de Hitler, a mera acusação de que uma pessoa tivesse 'sangue judeu' poderia ser suficiente para levar à agressão, prisão e até morte.

Hellman era descendente de judeus (por parte de pai), o que fortemente indica que além da questão política, certamente de interesse para uma autora como ela, havia também o lado pessoal a considerar. Reynolds (1986, p. 134) conclui seu argumento afirmando que a peça é "[...] uma acusação contra a sociedade que permite que tais questões sejam de qualquer maneira levantadas". Dessa forma, o autor contribui para equilibrar o peso das discussões: ao mesmo tempo em que não é possível desconsiderar a questão da homoafetividade na peça, não se deve atribuir a tal questão o maior peso, como fizeram Moody e Falk.

Moody é conservador ao atacar a confissão de Martha como algo que perturba a perspectiva heterossexual da peça. Para ele, a heterossexualidade de ambas as professoras justificaria a torcida da plateia por elas. Ao contrário de Moody, Falk exagera no tom progressista mencionando até mesmo o subconsciente para uma possível mudança na perspectiva de sentimentos (principalmente os de Karen). A peça não dá nenhuma base concreta, seja nos diálogos ou nas rubricas, para se acreditar que Karen nutra um sentimento que vá além do amor fraternal por Martha.

Michael Billington (2011), do jornal The Guardian, a respeito da encenação de The Children's Hour em Londres em 2011, expressa o mesmo pensamento que Moody, mesmo quase quatro décadas após a crítica desse último: "Nada pode disfarçar o fato de que esta é uma peça falha, na qual Hellman não se decide se ela está escrevendo sobre o poder corrosivo de falsas acusações ou o poder de uma paixão sexual oculta". As palavras de Reynolds, entretanto, não deixam dúvida sobre o que Hellman realmente escreveu.

Em seu artigo “Canonizing lesbians?”, Lynda Hart (1990, p. 277-278) problematizou a questão, incluindo em sua análise um panorama que, além de dialogar com a crítica tradicional, introduz a questão a homoafetividade como foco privilegiado de sua análise:

\footnotetext{
Primeiro, deixe-me alterar minha abordagem e perguntar se há uma lésbica no texto de Hellman. Martha é a única provável candidata, e ela não tem certeza sobre si mesma. Porque ela comete suicídio após a possibilidade lhe ocorrer, Hellman prematuramente encerra a questão. Hellman certamente permite que Martha anuncie 'Eu te amei do jeito que eles disseram', que pode soar como uma declaração de identidade lésbica ao espectador moderno. Entretanto, no contexto dessa peça, amar Karen 'do jeito que eles disseram', significa que Martha nutriu um desejo anormal, criminoso, possivelmente contagioso e certamente impronunciável por sua amiga. Eu posso então concordar com Hellman que sua peça não é absolutamente sobre lesbianismo, mas sobre uma mentira, a mentira arquitetada por sexólogos do século dezenove que construíram lesbianismo
} 
como um desejo 'invertido' mórbido.

Discordo da afirmação de Hart de que Martha não estava tão certa sobre sua condição. Ela estava tão certa que não teve dúvidas em cometer suicídio. Para Hart, a sentença "Eu te amei do jeito que eles disseram" de Martha é a manifestação de uma visão parcial e preconceituosa sobre o lesbianismo (nas palavras dela), que leva em conta apenas os fatores sexuais. Hart escreve em um tempo no qual o termo homoafetividade (homoaffectivity) começa a emergir, e como a própria palavra diz, as relações de pessoas do mesmo sexo são tratadas de um ponto de vista que já não é meramente sexual. A identificação por parte de Hart desse aspecto sexual na peça é importante porque indica sob qual perspectiva Hellman estava escrevendo.

A crítica de Hart expõe duas noções em embate e é preciso separá-las: a primeira noção diz respeito ao período no qual a peça foi escrita, em que a homoafetividade realmente era vista como inversão; a segunda, a maneira como a autora de The Children's Hour vê a questão. Quando Martha diz que ama Karen do jeito que outros disseram que ela amava, esta é a única forma que ela tem para dizer o que sente, isto é, ela se apropria do discurso de outros como forma de se expressar.

Ressalte-se que na época da escrita da peça e por décadas subsequentes o léxico da homoafetividade não estava disponível, provavelmente sequer existia, o que tornava comum o uso de palavras que aplicadas a situações de homoafetividade ganhavam contornos altamente pejorativos, tais como invertido, anormal, mórbido etc.

É inegável, como fica claro em várias cenas, que Martha não quer ver a amiga se casando e indo morar com Joe, o que evidencia que seus sentimentos por Karen não se resumem aos simplesmente sexuais: ela sabe que sentirá falta da convivência com a amiga, que após o casamento ficará restrita ao horário em que trabalharem juntas. Lynda Hart (1990, p. 278, grifo do autor) continua:

Minha resposta para a peça, no entanto, é embasada por uma perspectiva e uma política
lésbico- feminista dos anos 1980 . Historicamente, a peça foi baseada no julgamento de
1811 de duas professoras escocesas que foram absolvidas do 'crime' porque a
imaginação do seu juiz e júri não poderia imaginar o envolvimento de atividades sexuais
entre mulheres. Embora eu fique feliz pelas duas professoras que escaparam da prisão,
eu não me contento com uma peça que representa o amor lésbico como
impronunciável, invisível e impensável ocupando a posição por mais de cinquenta anos
como o único trabalho canonizado no moderno teatro americano 'sobre lesbianismo'.
[... A canonização de The Children's Hour revela uma inquestionável cumplicidade entre
heterossexismo por ocupar um espaço enquanto nenhuma outra peça 'sobre'
lesbianismo e nenhuma peça sequer de lésbicas declaradas tem esse questionável
privilégio.

Embora consistente, a explicação de Hart apresenta um problema que nada tem a ver com Lillian Hellman ou com a peça, a saber, a forma como a crítica se apropria e entende um objeto artístico, seja ele qual for. A peça foi um avanço enorme por ter exposto a questão da homoafetividade enquanto subjetividade. Prova desse avanço foram as medidas de retaliação adotadas para contê-lo: a peça foi banida em inúmeras cidades, a versão fílmica de 1936 (intitulada These Three) foi heteronormatizada ${ }^{6}$, a crítica era contra a confissão de Martha, entre outros. O descontentamento de Hart, portanto, poderia se concentrar mais ativamente no processo crítico que construiu The Children's Hour como representante (segundo ela, único) do moderno teatro norte-americano sobre "lesbianismo".

\footnotetext{
${ }^{6}$ Essa versão fílmica teve como roteirista a própria Lillian Hellman, que adaptou sua peça transformando-a em um filme no qual Karen não é amada por Joe e Martha, mas sim Joe é o objeto de amor das duas mulheres. A heteronormatização era necessária para que a peça pudesse ser adaptada, uma vez que o Código de Produção Cinematográfica (mais conhecido como Código Hays) proibia a exibição de "amor impuro" e que despertasse curiosidade ou simpatia (THE PRODUCTION, 2012).
} 
Sua crítica sem dúvida é válida, mas ao querer apontar deméritos na peça, Hart põe em dúvida a presença de The Children's Hour no cânone lésbico. Essa dúvida, entretanto, exige que algumas questões não sejam esquecidas: que lugar na dramaturgia norte-americana do século XX deve ocupar essa peça de Hellman, a primeira peça feminista de autoria feminina? Como não levar em conta que a peça causou enorme impacto e contribuiu para as discussões acerca da homoafetividade quando ficou em cartaz nos anos 1930 e 1950? Como desprezar o fato de que Hellman já levava aos palcos uma temática complexa quase duas décadas antes de alguns de seus contemporâneos?

Hart critica de uma perspectiva mais avançada a questão da confissão, contra a qual Brooks Atkinson notadamente se posicionou. Os críticos da primeira e segunda encenação foram contra o suicídio de Martha, mas seus motivos eram totalmente diferentes dos de Hart. Nos anos 1930 e 1950, eles queriam Martha viva para que ela enfrentasse as consequências do mal que Mary provocara; Hart critica o suicídio da personagem a fim de que a homoafetividade pudesse ser representada.

\section{ENTRE O SUSSURRO E A FALA: A HOMOAFETIVIDADE NA DISPUTA DA VEROSSIMILHANÇA}

Merece destaque outro ponto que diz respeito à sexualidade das alunas da escola. Embora não haja qualquer referência à prática sexual delas ou entre elas, sexo é um assunto pelo qual elas manifestam interesse e do qual sabem algumas coisas, mesmo não sendo - evidentemente - um assunto de sua grade escolar:

PEGGY (pula, bate a mão na boca). Ai, meu Deus! Rosalie vai encontrar aquela cópia de Mademoiselle de Maupin. Ela vai espalhar pra todo mundo.

MARY. Ah, ela não vai dizer uma palavra.

EVELYN. Quem fica com o livro quando nós mudarmos?

MARY. Pode ficar com você. Era isso que eu estava fazendo hoje de manhã terminando o livro. Tem uma parte nele -

PEGGY. Que parte?

(Mary ri)

EVELYN. Bem, o que era?

MARY. Espere até você ler. (HELLMAN, 1971, p. 25)

Publicado em 1835, Mademoiselle de Maupin (Senhorita de Maupin) é um romance epistolar escrito por Théophile Gautier. No romance acompanha-se a trajetória da personagem Madeleine de Maupin, uma mulher que se traveste (autonomeando-se Theodore) para viajar o mundo e conhecer os segredos dos homens antes de se entregar aos prazeres heterossexuais. Em seu caminho, Madeleine/Theodore cruza com D'Albert, que suspeita de seu disfarce e se apaixona por ela. Paixão semelhante atinge Rosette, uma conquista recente de D'Albert. No entanto, Rosette acredita na figura masculina de Theodore. Cria-se, assim, um triângulo amoroso tendo como pivô uma figura masculina e feminina ao mesmo tempo.

A avidez de Mary e das outras meninas para ler o livro e saber dos acontecimentos é grande. Logo após o castigo que Karen impõe a Mary, surge o assunto sobre o livro, e Peggy relata o que ouviu com Evelyn atrás da porta enquanto a Sra. Mortar e Martha discutiam:

PEGGY. Bem, a dona Lily disse que a dona Martha estava com ciúme deles e que era como quando ela era criança, e que seria melhor ela arranjar um namorado porque era anormal, e que ela nunca quis que ninguém gostasse da dona Karen, e que era anormal. Nossa! E a dona Martha ficou magoada com isso. (HELLMAN, 1971, p. 25)

A palavra anormal surge na fala de Peggy, reproduzindo o que ouviu da Sra. Mortar: "O que é anormal?" (HELLMAN, 1971, p. 25), pergunta a menina, ao que Evelyn responde: "A 
significa não. Não normal” (HELLMAN, 1971, p. 25). Mary, por sua vez, quer saber a que fato ou possibilidade a Sra. Mortar se referia quando acusava a sobrinha Martha de ter ciúme de Karen. Peggy e Evelyn não têm essa resposta, mas Mary terminara de ler naquela manhã o romance Mademoiselle de Maupin, que a proveu de imagens e ideias para inventar a mentira que contaria à avó não muitas horas depois.

Embora a princípio a avó não leve a sério o que Mary diz, quando a neta sussurra os detalhes imaginados, a Sra. Tilford se assusta e toma as suas providências drásticas que vão dar início à derrocada das professoras. O crítico teatral George Jean Nathan (1953, p. 51-52) comenta o sussurro de Mary em seu livro The Theatre in the Fifties (O Teatro nos Anos 1950):

\footnotetext{
Sempre houve um elemento nessa astuciosa peça que me incomodou. É a questão de a menina ter sussurrado suas acusações de perversão contra as duas professoras no ouvido de sua avó, porque ela afirma que não pode falar sobre o assunto em voz alta. Por que não pode? Tudo em seu caráter não apenas permitiria que ela falasse abertamente como iria deixá-la satisfeita. Não é a menina que está hesitante em articular tal assunto, é a dramaturga que evidentemente tem receio de colocá-lo em palavras e que se encolhe da possível censura (vide The Captive). Miss Hellman trapaceou.
}

Existe uma constante tentativa de classificar Mary como uma quintessência do mal, cruel a ponto de arquitetar a mentira e executá-la friamente. Porém, se fosse seguida a sugestão do crítico, a de colocar o assunto em palavras, haveria o reforço do aspecto da sexualidade na peça, o qual sempre foi dito ser um aspecto secundário (tanto por Hellman quanto por críticos que entenderam melhor a dimensão da peça). Não houve trapaça: The Children's Hour foi censurada, a versão fílmica de 1936 foi heteronormatizada. Caso o sussurro de Mary ganhasse o status de fala, a mentira ganharia tanta expressão quanto a confissão de amor de Martha. O que Hellman fez é algo bem mais efetivo: favoreceu a verdade declarada (ou a declaração-confissão de amor) e manteve a mentira em um sussurro.

Para Charles Spencer (2011), do jornal The Telegraph, "A peça está longe de ser perfeita. É difícil acreditar que a avó [interpretada por Ellen Burstyn] acreditaria tão prontamente nas acusações da neta [...]". A mesma dúvida é compartilhada por Michael Billington (2011): “[...] leva-se um longo primeiro ato para armar a situação e fica-se admirado com a facilidade com a qual acreditam em Mary". O fato mais importante é que quem primeiro acredita em Mary é a própria avó e ela só faz isso após o tão criticado sussurro. Para esses críticos, provavelmente ainda perdure o desejo de transformar o sussurro em fala.

Porém, não se pode negar a força de argumentação de Mary: ela convence as colegas da escola a ajudarem-na, enfrenta Martha e Karen não admitindo ser desmascarada (por isso finge o desmaio) e chantageia Rosalie para corroborar sua história. Some-se a isso o fato de que ela leu pelo menos um livro (é provável que tenha lido muitos outros) do qual tirou ideias para inventar a mentira. O fato de a Sra. Tilford acreditar na neta, portanto, nada tem de inverossímil, especialmente se for levado em conta que as invenções de Mary sobre o que as professoras faziam no quarto eram impensáveis para uma menina na década de 1930.

\section{CONSIDERAÇÕES FINAIS}

Nos anos 1930 e 1950, a crítica cobrava que não houvesse suicídio e que ambas as professoras fossem deixadas juntas em desespero. Nos agitados anos 1960, fatores como militância e politização despertavam atenção, enquanto nos anos 1980 e 1990, teóricos rejeitavam a peça como um texto representante da homoafetividade. Em 2011, críticos ainda retomam aspectos da peça bem feita e do melodrama levantados há décadas.

Após a exposição desse panorama de críticas ao longo de várias décadas, conclui-se que mesmo tendo ganhado novos contornos em relação à homoafetividade, a avaliação continuou desfavorável no que concerne às escolhas formais de Hellman. Esse procedimento crítico tem 
contribuído fortemente para que a peça continue estigmatizada sob os rótulos de bem feita e, especialmente, melodramática.

Lynda Hart afirma que The Children's Hour alcançou injustamente o cânone do teatro feminino e lésbico. Cabe aos estudiosos e interessados na obra de Lillian Hellman ajudar a estabelecer qual o lugar dessa sua obra na dramaturgia norte-americana do século XX. É certo que ela não pode ser restrita a cânones identitários e muito menos ficar fora do cânone geral.

\section{REFERÊNCIAS}

ATKINSON, Brooks. At the theatre. New York Times. New York, 28 Dec. 1952. p. X1. Children’s Hour. New York Times. New York, 2 Dec. 1934b. p. XI.

The Play: “The children's hour", being a tragedy of life in a girls' boarding house. New York Times, New York, 21 Nov. 1934a. p. 23.

BENCHLEY, Robert. The theater: good news. New Yorker, New York, p. 34-36, 1 Dec. 1934.

BILLINGTON, Michael. The children's hour - review. The Guardian (online), 10 Feb. 2011. Disponível em: <http://m.guardian.co.uk/stage/2011/feb/10/the-childrens-hourreview?cat $=$ stage\&type $=$ article $>$. Acesso em: 10 Out. 2011.

FALK, Doris V. Lillian Hellman. New York: Frederick Ungar Publishing Co., 1978. 180p.

FLORES, Fulvio Torres. Nem só bem feitas, nem tão melodramáticas: “The children's hour" e "The little foxes", de Lillian Hellman. 2008. 289 f. Dissertação (Mestrado) - Faculdade de Filosofia, Letras e Ciências Humanas, Universidade de São Paulo, São Paulo, 2008.

HART, Lynda. Canonizing lesbians? In: SCHLUETER, June (Org.). Modern American drama: the female canon. London and Toronto: Associated University Presses, 1990. p. 275-292.

HELLMAN, Lillian. The children's hour. In: The collected plays. Boston, Toronto: Little, Brown \& Co., 1971. p. 1-71.

MOODY, Richard. Lillian Hellman: playwright. New York: Pegasus, 1972. 372p.

NATHAN, George Jean. The theatre in the fifties. New York: Alfred A. Knopf, 1953. 298p.

REYNOLDS, R. C. The well-made melodrama. In: Stage left: the development of the American social drama in the thirties. Troy, NY: Whitston, 1986. p. 128-144.

SPENCER, Charles. The children's hour, Comedy Theatre, London. The Telegraph (online), 10 Feb. 2011. Disponível em: <http://www.telegraph.co.uk/culture/theatre/theatrereviews/8315448/The-Childrens-Hour-Comedy-Theatre-London.html>. Acesso em: 23 Oct. 2011. 
THE PRODUCTION CODE. The Motion Picture Production Code of 1930 (Hays Code). Disponível em: <http://www.artsreformation.com/a001/hays-code.html>. Acesso em: 17 jun. 2012.

TREWIN, J. C. Introduction. In: Plays of the year 1950-1951. London; New York: Elek Books, 1952. p. 7-12.

Recebido em 06/04/2014

Aprovado em 10/08/2014 